\title{
A (I)licitude das provas envolvendo intimidade e imagem de cônjuges nas ações exoneratórias de alimentos
}

\author{
The illicitude of evidence involving intimacy and image of spouses in alimony \\ exonerating actions
}

\author{
Tereza Cristina Monteiro Mafra* \\ Marina Nogueira Resende Silva*
}

\section{Resumo}

O presente artigo tem como foco a análise da hipótese de violação da intimidade e da imagem de pessoa casada pelo outro cônjuge mediante a divulgação não consentida de conteúdo e dados obtidos na constância do casamento. Temse como objetivos identificar os limites de interferência na esfera da intimidade e da imagem, bem como verificar até que ponto o segredo poderá ser protegido na esfera familiar, tendo em vista os impactos da comunhão plena de vida promovida pelo casamento. Para tanto, investigou-se a forma de solução mais viável para solucionar conflitos entre o direito ao segredo e a proteção da confiança, especialmente no Direito de Família e nas ações de alimentos. Discutese ainda sobre a (i)licitude de provas obtidas na constância do casamento, que expõem a intimidade e imagem de um cônjuge quando o outro invoca procedimento indigno como causa exoneratória de alimentos. Para tanto, a pesquisa se desenvolveu com base na doutrina e jurisprudência, bem como na legislação acerca do tema. Conclui-se que deverá haver uma apreciação do caso concreto, caso haja prejuízo a alguma das partes, assim como nas situações em que as informações houverem sido obtidas de forma ilícita, com uma necessária ponderação dos princípios envolvidos.

Palavras-chave: Comunhão de vida. Intimidade. Imagem. Alimentos. Procedimento indigno.

\section{Abstract}

The present article focuses on the analysis of the hypothesis of violation of the intimacy and the image of married person by the other spouse through the non-consented disclosure of content and data obtained in the constancy of the marriage. The objective is to identify the limits of interference in the sphere of intimacy and image, as well as to verify to what extent the secret can be protected in the family sphere, in view of the impacts of the full communion of life promoted by marriage. To do so, we investigated the most viable solution to solve conflicts between the right to secrecy and the protection of trust, especially in Family Law and in food actions. There is also a discussion of (i) the lawfulness of evidence obtained in the constancy of marriage, which exposes the intimacy and image of a spouse when the other invokes unworthy procedure as an exoneratory cause of food. To do so, the research developed on the basis of doctrine and jurisprudence, as well as in legislation on the subject. It is concluded that there should be an assessment of the specific case, if there is damage to any of the parties, as well as in situations where information has been obtained illegally, with a necessary consideration of the principles involved.

Keywords: Communion of life. Intimacy. Image. Alimony. Unworthy procedure.

\section{Introdução}

Os direitos da personalidade ligam-se à própria existência humana, com incidência que antecede o nascimento, e a projeções post mortem, para além da pessoa de sua titularidade, envolvendo a família de

\footnotetext{
Doutora em Direito Civil pela Universidade Federal de Minas Gerais. Mestre em Direito Civil pela Universidade Federal de Minas Gerais. ViceDiretora da Faculdade de Direito, Coordenadora Geral da Pós-Graduação em Direito e Coordenadora da Área de Direito Civil da Faculdade de Direito Milton Campos. Professora da Pós-Graduação em Direito Civil da Faculdade de Direito Milton Campos e de Direito de Família e Sucessões da Faculdade Arnaldo. Professora do Curso Preparatório do Ministério Público de Minas Gerais (FESMP). Advogada. Belo Horizonte - MG - Brasil. E-mail: tereza.c.mafra@terra.com.br.

Mestranda em Direito nas Relações Econômicas e Sociais das Faculdades Milton Campos. Advogada. Belo Horizonte - MG - Brasil. E-mail: marinanresende@gmail.com.
} 
que faz parte. O seu desenvolvimento se deu especialmente no século XX, depois das Guerras Mundiais, nas Declarações Internacionais que determinaram a tutela da pessoa humana.

No mesmo período, o Direito de Família também sofreu intensas transformações. A família progressivamente perdeu sua concepção como espaço e função econômicos, passando a serem destacados os laços afetivos. O respeito aos sentimentos tornou-se mais importante que a vontade de proteção ao patrimônio. Identificam-se, a partir de então, as raízes de um fenômeno de democratização e personalização da família, que passa a ser pautada pela igualdade, e seus integrantes passam a buscar proteção às pessoas.

Trata-se de dois universos distintos, mas com inegável interseção. O Direito de Família regula os direitos e deveres das pessoas como integrantes de uma entidade familiar, e os direitos da personalidade se voltam, prioritariamente, para a proteção dos direitos originários da pessoa, mais que do grupo do qual ela possa fazer parte.

Assim sendo, no presente estudo, elegeu-se uma abordagem dos direitos da personalidade e seu entorno familiar, especificamente acerca da proteção da imagem e da intimidade na relação conjugal e a violação de tais direitos por determinadas divulgações realizadas em ações de alimentos entre cônjuges.

Ocorre que, apesar de toda a amplitude da comunhão de vida gerada pelo casamento, é necessário um espaço de segredo na vida familiar, que deve ser respeitado pelos cônjuges e demais membros da família. É que as pessoas, casadas ou não, têm, naturalmente, o profundo desejo de inibir o olhar alheio sobre suas vidas, na mesma medida em que todos têm algo que preferem não tornar público. Tal se dá desde o instante quando se sente a necessidade vital de se proteger dos outros.

Lato sensu, o segredo se apresenta como um instrumento, inconsciente ou não, de proteção contra o mundo exterior, e se manifesta em diferentes categorias de pessoas e domínios: as pessoas naturais, quanto à sua vida privada; a pessoa jurídica, empresária ou não, quanto a informações sobre suas atividades; o Estado, em relação a certos aspectos de sua política.

Os segredos são da essência do homem e muitos podem ter por objeto a pessoa e a família de que ela faz parte, mas cumpre indagar até que ponto se deve admitir a interferência na esfera da intimidade. De outro lado, tendo em vista que as relações familiares geram também efeitos patrimoniais, como solucionar os eventuais conflitos entre segredo e proteção da confiança, especialmente nas ações de alimentos?

O assunto abordado neste artigo é a (i)licitude da divulgação de conteúdo íntimo de pessoas casadas em ações de alimentos, visando configurar procedimento indigno como hipótese exoneratória. Trata-se de assunto delicado, exigindo-se grande cautela. Por diversas vezes, ex-cônjuges ingressam em verdadeiras batalhas judiciais e extrajudiciais para fazerem valer seus próprios direitos ou simplesmente suas vontades.

Pessoas casadas costumeiramente compartilham intimidades durante o decorrer do relacionamento, seja por meio de informações e documentos, seja até mesmo por imagens. Podem chegar a armazenar todo esse conteúdo íntimo, estando ou não de má-fé. Além disso, pode-se questionar a respeito da possibilidade de um dos cônjuges não compartilhar de forma ampla sua intimidade com o parceiro, e a existência de respaldo legal para essa conduta.

Em caso de término do relacionamento, surge a indagação de até onde o conteúdo que foi compartilhado pode ser exposto por uma das partes a fim de produzir prova contra o outro, tendo em vista que a única forma de obtenção de determinadas informações é por meio da convivência que existia anteriormente.

Para a análise em questão, foram estudados alguns direitos da personalidade que podem ser lesados, tal como o direito de proteção à intimidade, à privacidade e à imagem, de um lado, e, por outro lado, a comunhão plena de vida como cláusula geral do casamento, a fim de analisar até que ponto esses institutos se adequam ou conflituam. Ademais, apresenta-se análise da proteção da confiança no 
casamento e os respaldos existentes, para, finalmente, verificar a possibilidade de exoneração do dever de prestar alimentos por procedimento indigno, e como a prova disso, eventualmente, pode ou não afrontar a proteção do segredo na relação conjugal.

Tais são os principais questionamentos aqui apresentados e desenvolvidos, sem a pretensão de esgotar o tema, adotando-se como marco teórico a concepção de Pontes de Miranda (1971), em Tratado de Direito Privado, que subtipifica o direito de respeito à vida privada em direito à intimidade e direito ao segredo, e define o segredo da vida privada como a liberdade de não emitir o pensamento para todos ou além de certas pessoas. Para a realização da pesquisa foi utilizado o método documental, por meio de coleta e revisão de artigos sobre a proteção do segredo e o direito de estar só, assim como monografias relacionadas ao assunto, doutrina específica, reportagens e jurisprudências sobre o tema.

\section{Comunhão de vida e o direito de estar só}

A comunhão de vida decorre do casamento, como se depreende do texto legal, mas é também sua principal finalidade, como já alertava Lafayette Rodrigues Pereira (2004, p. 29-30), no seu clássico Direitos de Família, escrito antes do Decreto $n^{\circ} 181$, de 1890, que instituiu o casamento civil no Brasil:

O fim capital, a razão de ser dessa instituição, está nessa admirável identificação de duas existências, que, confundindo-se uma na outra, correm os mesmos destinos, sofrem das mesmas dores e compartem, com igualdade, do quinhão de felicidade que a cada um cabe nas vicissitudes da vida.

Embora se referindo ao "novo Direito de Família", ainda na década de 1980, Orlando Gomes (1981, p. 25) afirmava que "o primeiro e mais importante princípio do novo Direito de Família é o que põe a ratio, o fundamento básico do matrimônio e da vida conjugal na afeição entre os cônjuges e a necessidade de que perdure completa comunhão de vida".

O art. 1.511 do Código Civil vigente dispõe que "o casamento estabelece comunhão plena de vida, com base na igualdade de direitos e deveres dos cônjuges". Essa previsão é complementada pelo disposto no art. 1.565, pelo qual o Codex estabelece que: "Pelo casamento, homem e mulher assumem mutuamente a condição de consortes, companheiros e responsáveis pelos encargos da família". Daí advém a noção de solidariedade entre os cônjuges, que fundamenta os deveres conjugais, consoante lição de Carlos Dias Motta (2007, p. 307) e Diogo Leite Campos (1990, p. 247-249).

Por outro lado, de acordo com Celso Lafer (2002, p. 141-142), a comunhão de vida é dominada pelo que chamou de princípio da exclusividade:

Para a tutela da dignidade humana exige-se, além da luz da esfera pública, 'a proteção das sombras que permitem a transparência dos sentimentos da vida íntima', a exclusividade regendo aquela especial esfera da vida privada em relação à qual é defesa a interferência alheia, pois é o locus, material e espiritual, no qual escolhemos aqueles com os quais desejamos passar nossas vidas, amigos pessoais e aqueles que amamos.

O princípio da exclusividade representa um limite à interferência alheia no casamento, tanto do Poder Público quanto de terceiros, e "mantém na decisão da família a sua intimidade, o seu modo de ser particular" (MARTINS-COSTA, 2002, p. 142).

No casamento, a proteção da intimidade se destina à preservação, tanto do grupo familiar como também dos membros do grupo. As aspirações de cada indivíduo podem florescer na intimidade da vida conjugal, tendo a família como o "lugar privado", onde os sentimentos e as emoções podem se desvendar entre o casal.

Nesse contexto, o lar conjugal apresenta-se como um espaço no qual as pessoas podem estar a salvo de intrusões indesejadas, onde estão livres para usufruir o seu mundo interior, segundo Milton 
Fernandes (1977, p. 158-159). Entretanto, cumpre indagar se os casados têm, um cônjuge em relação ao outro, o direito de estar só.

Para tratarmos das relações partilhadas entre cônjuges e sua eventual violação, precisamos primeiramente definir no que consiste o direito à intimidade, que é um importante direito da personalidade respaldado pela legislação, inclusive na Carta Magna. Ademais, deve-se ressaltar que se trata de direito que se mantém mesmo na constância do casamento:

\begin{abstract}
Art. $5^{\circ}$ Todos são iguais perante a lei, sem distinção de qualquer natureza, garantindo-se aos brasileiros e aos estrangeiros residentes no País a inviolabilidade do direito à vida, à liberdade, à igualdade, à segurança e à propriedade, nos termos seguintes:

$[\ldots]$

X- são invioláveis a intimidade, a vida privada, a honra e a imagem das pessoas, assegurado o direito a indenização pelo dano material ou moral decorrente de sua violação;
\end{abstract}

Está previsto também em legislação infraconstitucional, no Código Civil brasileiro: "Art. 21. A vida privada da pessoa natural é inviolável, e o juiz, a requerimento do interessado, adotará as providências necessárias para impedir ou fazer cessar ato contrário a esta norma". É importante definir o que são os direitos da personalidade, por serem os principais a serem lesionados quando conteúdos íntimos são compartilhados sem autorização. O doutrinador Silvio Rodrigues (1994, p. 81) descreve que os direitos da personalidade são inerentes à pessoa humana, ligados a ela de forma perpétua e permanente, não se podendo conceber um indivíduo que não possua direito à vida, liberdade física, intelectual, ao seu nome, ao seu corpo, à sua imagem, e o que ele crê ser sua honra. Portanto, o direito à intimidade e diversos outros direitos da personalidade são intrínsecos aos indivíduos. Não cessam com adventos da vida cível.

O direito à intimidade está relacionado de forma especial ao direito à imagem. Isto porque, por diversas vezes, a intimidade é violada por meio da divulgação da imagem e de conteúdos relacionados a ela. Partindo desse pressuposto, Sampaio (1998, p. 377) leciona sobre o direito à imagem:

Como objeto de um direito, o direito à imagem, a experiência jurídica a tem associado componentes que, embora inter-relacionados com a noção supracitada, destaca-se na precisa definição dos poderes atribuídos a seus titulares: negativos: de oposição à sua realização, produção, reprodução e divulgação, enfim, ao conhecimento alheio; positivos: de consentir com tudo isso.

Em seguida, Sampaio (1998, p. 374) leciona sobre informações pessoais e sua inviolabilidade, com a conceituação do segredo: relata que se trata de um direito a controlar o uso de informações pessoais que não se contêm no âmbito do domínio fático das informações, de sua exclusividade, que fazem parte do conceito de segredo, mas mesmo que as informações tenham saído desses domínios, a pessoa continua exercendo um controle sobre a destinação do conteúdo.

Paulo José da Costa Junior (2007, p. 31-32), desenvolvendo a teoria dos círculos concêntricos, aponta a existência de três esferas da vida privada. No círculo externo está a esfera privada stricto sensu, compreendendo todos os comportamentos e acontecimentos que a pessoa não quer tornar públicos. Dentro dessa esfera está a da intimidade, da qual participam apenas aqueles com os quais a pessoa deposita confiança, envolvendo conversações ou acontecimentos íntimos. E, por fim, na parte central está a esfera do segredo, que compreende a parte mais íntima da pessoa.

Para Milton Fernandes (1977, p. 71), o menor dos círculos concêntricos "compreende a parcela da vida particular que é conservada em segredo pelo indivíduo, do qual compartilham, quando muito, alguns amigos apenas. Desta esfera não participam sequer as pessoas da intimidade do sujeito". Em princípio, a cada pessoa, casada ou não, deve ser assegurada a esfera do segredo, na qual se resguarda, inclusive, de que o outro cônjuge se imiscua.

A existência de segredos que um cônjuge decide manter desconhecido do outro caracteriza o comportamento do indivíduo de querer preservar seu espaço privado e sua individualidade, em relação até mesmo à pessoa com quem decidiu estabelecer uma comunhão de vida. 
O individualismo pode parecer antinômico com o princípio da solidariedade, que é a base dos deveres conjugais. Mas a pessoa, mesmo casada, mantém a sua singularidade e pode pretender resguardar um espaço no qual abrigue certos aspectos de sua vida.

Entretanto, embora haja interesses legítimos a serem colocados a salvo da ciência do cônjuge, pelo casamento são estabelecidos limites, determinados pela justa expectativa de cumprimento dos deveres do casamento, tanto no campo pessoal, quanto no patrimonial.

Conquanto não seja objeto do presente estudo a análise dos Direitos Pessoais, vale, a título de exemplo, explicitar que, certas circunstâncias, características ou acontecimentos anteriores ao casamento devem ser conhecidas pela pessoa com quem se casa, sob pena de se configurarem como hipóteses de anulabilidade do casamento, por erro essencial quanto à pessoa do outro cônjuge (arts. 1.556 e 1.557 do $\mathrm{CC})$.

Desde 2010, com o advento da Emenda Constitucional n 66, o divórcio se tornou um direito potestativo e a inculpação no fim do casamento chegou ao fim. Os deveres conjugais se vêem funcionalizados para preservar a comunhão plena de vida - cláusula geral do casamento.

À semelhança do BGB, em lugar de uma indicação pormenorizada dos deveres do casamento, o legislador brasileiro adotou uma cláusula geral (o §1.353 do BGB dispõe que os cônjuges estão mutuamente obrigados à comunhão conjugal de vida), "que é para todo o direito matrimonial ao mesmo tempo linha de interpretação para as normas de direito matrimonial existentes e preenchimento de lacunas para as normas de direito matrimonial não existentes" (SCHLÜTER, 2002, p. 106).

A comunhão plena de vida concretiza a intenção conjugal, objeto principal da união, e se exterioriza pela convivência entre os cônjuges, que compartilham afetos e interesses comuns. A especificação contida no art. 1.566 tem a função de instituir deveres e limitar os comportamentos a que ficam sujeitos os cônjuges. De acordo com Pinheiro (2004, p. 85-91), na pesquisa do conteúdo dos deveres conjugais, é essencial a noção social do que deve ser o casamento:

Há um mínimo de que depende a especificidade do instituto e que não pode ser atingido pela autonomia privada, nem por uma perspectiva hipertrofiada da liberdade individual. Esse mínimo, o núcleo intangível do casamento, não se traduz em meras posições jurídicas típicas de quem pertence a uma organização econômica. Reflete-se sobretudo na esfera mais pessoal das partes.

Assim, conquanto os direitos conjugais tutelem prioritariamente os cônjuges, eles não se restringem ao interesse egoísta de seus titulares (DABIN, 1952, p. 250-251), encontrando limites na sua funcionalidade de assegurar a comunhão plena de vida. Logo, tanto no erro essencial quanto na inobservância dos deveres do casamento, as pretensões de desfazimento do vínculo conjugal se amparam na insuportabilidade da vida em comum, sendo certo que, apenas nas hipóteses de invalidade, serão investigados aspectos ligados ao âmago da intimidade das pessoas, os quais, uma vez comprovados, justificarão o desfazimento do enlace conjugal mediante determinação judicial.

Contudo, ainda que sejam objeto de discussão judicial, tais conteúdos não deverão ser armazenados, processados, tratados, comunicados, transmitidos, divulgados ou publicados, a não ser que seja inequivocamente dada a devida autorização. Portanto, a licitude está vinculada à vontade do interessado, que será quem poderá relativizar a veiculação de dados sobre sua intimidade e imagem.

Partindo desse pressuposto, de acordo com Beltrão (2005, p. 129), o direito à vida privada considera a autonomia da pessoa de tomar decisões a respeito de assuntos íntimos, revelando-se como garantia de independência e inviolabilidade da pessoa. Ademais, ele afirma que a definição do conteúdo e a dimensão que a pessoa dá ao seu direito à vida privada está relacionada ao estudo dos fenômenos sociopsíquicos, em que os valores vigentes de cada época e lugar influenciam o indivíduo. A partir desses valores, ele possui a necessidade de resguardar do conhecimento de outras pessoas os aspectos mais particulares de sua vida. 
Normalmente, os cônjuges são pessoas íntimas que partilham uma vida comum e dividem suas vidas privadas. Deve-se diferenciar a vida privada da pública para a confirmação do entendimento.De acordo com Manoel Gonçalves Ferreira Filho (1999, p. 90), vida privada é a que se desenvolve fora das vistas do público, diante, eventualmente, de um pequeno grupo de pessoas íntimas. Portanto, é a comumente dividida por cônjuges - o que não significa que a pessoa casada perca todo o espaço para o segredo. A comunhão plena de vida não significa a perda da proteção da intimidade.

Novamente retomamos o direito à intimidade e sua esfera pessoalíssima. Podemos considerar que estão incluídos: o direito de estar só, poder guardar determinadas informações para si mesmo, assim como fatos de sua própria vida, medos, crenças, convicções, excentricidades. Por ser matéria de foro íntimo, não precisa ultrapassar a esfera da própria pessoa, a não ser que ela decida compartilhar por vontade própria.

Elimar Szaniawski (2005, p. 315) narra que, apesar de existirem relações conjugais e de filiação, é imprescindível a existência de um mínimo de intimidade e de segredo na vida familiar, o qual deve ser respeitado, tanto pelos cônjuges entre si quanto entre pais e filhos, irmãos, e demais pessoas que viverem sob o mesmo teto. Dessa forma, a coabitação entre os membros da mesma família não exclui o dever de respeito da intimidade e do segredo. Alguns autores denominam de segredo familiar essa esfera dos membros da família em relação aos demais membros, protegendo e tutelando a liberdade das relações familiares.

Nesse mesmo sentido, Paulo José da Costa Jr. (1970, p. 77) aponta como formas de violação de segredo a gravação de conversas íntimas, por meio de microfones ocultos ou por meio de fotografias e filmagens por câmeras poderosas, que estejam escondidas ou dentro de objetos localizados no interior da casa. A respeito da matéria, Szaniawski (2005, p. 316) relata que, se a violação por intermédio de espionagem acústica ou fotográfica for realizada por alguém que more na mesma residência, por exemplo, um marido espionando a esposa por ciúmes, haveria a violação do direito ao segredo familiar, considerandose esse fato como um grave atentado à intimidade da vida privada de quem é espionado. Resta verificar se a divulgação de imagens e conteúdos íntimos em juízo, com o objetivo de comprovar procedimento indigno para fins exoneratórios de alimentos, constitui prova lícita.

\section{Procedimento indigno versus proteção da intimidade e da imagem}

O ponto principal deste artigo é a utilização de conteúdo que envolva a intimidade de pessoas casadas para a concessão de alimentos. O parágrafo único do art. 1.708 do Código Civil dispõe:

Art. 1.708. Com o casamento, a união estável ou o concubinato do credor, cessa o dever de prestar alimentos.

Parágrafo único. Com relação ao credor cessa, também, o direito a alimentos, se tiver procedimento indigno em relação ao devedor.

Disto se conclui que existindo procedimento indigno do credor em relação ao devedor, cessa o direito a alimentos, ou seja, a indignidade é causa de exoneração dos alimentos. Este dispositivo legal traz consequências graves, tendo-se em vista que, mesmo havendo uma situação de dependência do credor, seja econômica, seja afetiva, haverá a perda do direito aos alimentos em caso de indignidade.

Faz-se necessário um esclarecimento a respeito do que seria a indignidade nestes casos, tendo-se em vista que não há definição clara pelo diploma. Podem-se trazer à tona as hipóteses de indignidade em casos sucessórios, conforme entendimento consubstanciado no Enunciado 264, aprovado na III Jornada de Direito Civil promovida pelo Centro de Estudos Judiciários do Conselho da Justiça Federal: "Art. 1.708: $\mathrm{Na}$ interpretação do que seja procedimento indigno do credor, apto a fazer cessar o direito a alimentos, aplicam-se, por analogia, as hipóteses dos incisos I e II do art. 1.814 do Código Civil". Assim, seriam indignos os atos atentatórios contra a vida e a honra do alimentante. 
Deve-se ressaltar que esta é apenas uma referência ao direito sucessório, pois a legislação pátria não esclarece quais os limites da configuração do procedimento indigno para fins de perda do direito aos alimentos.

O art. 2019 do Código Civil de Portugal estabelece que cessa a obrigação alimentar quando o alimentado se tornar indigno do benefício pelo seu comportamento moral, sendo que a doutrina recomenda utilizar esse dispositivo quando a imoralidade for de tal ordem que pareça razoável entender como inexigível o encargo (COELHO, 2008, p. 706). Sobre o tema, também é cabível destacar a lição de Paulo Lôbo (2010, p. 392):

Por sua natureza de restrição de direitos, o conceito de procedimento indigno deve buscar seu conteúdo no sistema jurídico, quando delimita o significado de indignidade, para os fins civis, evitando-se os juízos subjetivos ou valores morais do ex-cônjuge e do próprio magistrado. Pode o juiz determinar que, em vez da extinção haja redução dos alimentos, para assegurar a subsistência do alimentando. O Código Civil [arts. 1.814, 1.815, 1.962 e 1.963] considera casos de indignidade, também aplicáveis à extinção do direito de alimentos de ex-cônjuge ou ex-companheiro: a) a tentativa de homicídio contra o alimentante e seus descendentes; b) a acusação caluniosa ou o cometimento de crime contra a honra do alimentante; c) a utilização de meios fraudulentos para obtenção dos alimentos; d) a ofensa física; e) relações ilícitas com o cônjuge ou companheiro de filho, filha, neto ou neta do alimentante; f) o desamparo de filho ou neto com deficiência mental ou grave enfermidade.

A jurisprudência pátria acolhe a tese da perda do direito a alimentos por comportamento indigno do pretenso alimentando:

Ementa: - Conforme excelente lição de Yussef Said Cahali, na obra ‘Dos Alimentos', $3^{\mathrm{a}}$ ed., ed. RT, p. 747 'O trabalho é obrigação social, a mulher, sendo válida, pode concorrer para a própria subsistência com o produto de seu esforço.'- Provado que sobrevieram alterações nas condições financeiras das partes, e até mesmo que a alimentada agiu de forma indigna relativamente ao alimentante, é de se exonerar aquele da obrigação alimentar. Inteligência dos arts. 1699 e 1708, parágrafo único, CC. (MINAS GERAIS. TJMG - 7ª CÂMARA CÍVEL - APELAÇÃO CÍVEL № 1.0261.07.052539-7/001 Relator: Des. EDIVALDO GEORGE DOS SANTOS - Data do Julgamento: 26/02/2008)

Ementa: Separação Judicial litigiosa - Hipótese em que não se confirma prática de conduta desonrosa ou grave violação dos deveres do casamento durante a coabitação, apurando-se, sim, ter a mulher, na fase de separação de fato, praticado crime contra os costumes e contra os filhos menores, o que justificou condenação em processo criminal, com trânsito em julgado - Não obstante sem definição da culpa, preserva-se a separação ditada pela insuportabilidade da vida em comum, prestigiada a partilha de bens adquiridos durante o matrimônio - Acolhimento do recurso, porém, para reconhecer a exoneração do dever de o autor pagar alimentos à ré em razão do comportamento indigno da ex-mulher, nos termos do parágrafo único, do art. 1.708, do CC - Recurso provido, em parte, para esse fim. (SÃO PAULO. TJSP - $4^{\text {a }}$ Câmara de Direito Privado - APELAÇÃO Nº: 994.09.317448-4 Relator: Des. Enio Zuliani - Data do julgamento: 13/05/2010).

Na doutrina de Fredie Didier Júnior et alii (2005, p. 383): "A única hipótese que ensejará extinção do direito a alimentos também para os parentes é a prevista no parágrafo único, do art. 1.708, do novo Código Civil, a saber, a hipótese consistente no procedimento indigno do credor em relação ao devedor de alimentos".

Cuida-se de um caso especial de proteção à honra do eventual devedor de alimentos, a exemplo do que ocorre com a revogação da doação. De acordo com Aparecida Amarante (2005, p. 182), o legislador brasileiro "retornou ao preceito das Ordenações Filipinas que contemplava a ingratidão, além de outras causas, para isentar o pai da prestação alimentícia se o filho cometera ingratidão pela qual pudesse ser deserdado".

Portanto, sendo vasto o conceito, podemos considerar diversos casos distintos de indignidade, em que uma parte fira a imagem da outra, principalmente perante terceiros. Existem diversas possibilidades razoáveis que se enquadram nessa hipótese. Devemos trazer para análise o caso apresentado neste 
artigo: a indignidade por meio de divulgação não autorizada de conteúdo íntimo adquirido na constância do casamento.

Este conteúdo pode se apresentar de diversas formas: imagens sensuais tiradas durante o relacionamento; filmagens íntimas; informações compartilhadas anteriormente e que apenas os parceiros tinham ciência; assim como detalhes sobre condições médicas, como depressão e transtornos mentais (leves ou graves) controlados por meio de medicação; gravações telefônicas não autorizadas; interceptação de correspondência; dentre outros.

Há a possibilidade de uma das partes acumular durante a relação o maior número de comprovação que conseguir, já tendo em mente a finalidade comprobatória em batalha judicial posterior. Algumas dessas informações, como a existência de certas condições mentais, podem ser usadas para descreditar a outra parte, mesmo que a pessoa esteja devidamente medicada e a doença não atrapalhe em nada as suas funções habituais.

Outra possibilidade que deve ser vislumbrada em caso de pensão alimentícia a um dos cônjuges é o armazenamento de imagens e vídeos que comprovem relações extraconjugais, por meio do acesso não autorizado ao celular do cônjuge, para serem utilizados em momento posterior, facilitando a não concessão de alimentos após o divórcio.

Pontes de Miranda (1971) justifica a realização de investigações na vida privada ou pública de alguém, caso elas possam ser justificadas por um direito mais alto. Exemplifica como causas que autorizariam essas investigações, por exemplo, a investigação da saúde do noivo(a), a fim de ser constatado se é portador de doenças transmissíveis, e a prática de adultério pelo cônjuge, como acima mencionado.

A divulgação desses conteúdos em geral pode ocorrer em momento posterior ao casamento, com a finalidade de causar prejuízo ao outro cônjuge no momento de determinação de concessão de pensão alimentícia, utilizando-se da informação extraída do casamento para impedir o cônjuge de receber pensão.

Lourival de Jesus Serejo Sousa (1999, p.10) afirma que constantemente são utilizadas escutas telefônicas, gravações clandestinas e até mesmo são contratados detetives particulares em processos de separação judicial e em batalhas de custódia de filhos, pois mesmo sendo adquiridas de maneira não ortodoxa, são formas diretas de comprovar determinadas situações. Todos esses casos devem ser analisados atentamente! A primeira coisa que deverá ser considerada é a licitude da prova utilizada e os meios que a mesma foi adquirida. No ordenamento jurídico existem diversas correntes a respeito da matéria. De acordo com Eduardo Cambi (2006, p. 40):

\footnotetext{
A busca da verdade não é um valor absoluto no processo e tampouco justifica ir ao seu encalço a qualquer preço. Ela precisa ser temperada com os demais valores presentes no contexto processual e assim naturalmente sujeita às restrições dos excessos e desvarios de uma incontida ilicitude, tudo em consideração a valores de maior estatura moral.
}

Fernando de Almeida Pedroso (1986, p. 163) afirma que, considerando que o fim precípuo do processo é a descoberta da verdade real, se a prova obtida ilicitamente demonstrar essa verdade, ela deverá ser admissível, mesmo que o Estado tenha que sancionar o agente que infringiu as disposições legais e os direitos do réu. Este é um exemplo que representa os argumentos da corrente que apóia a admissibilidade. Em mesmo sentido, Yussef Said Cahali (1991, p. 726) pensa que não é relevante se o material foi obtido de forma ilícita ou desleal, ou até mesmo interceptada, devendo, em sua opinião, os julgadores decidirem se as provas apresentadas são hábeis para formar um juízo de convicção, independentemente de interceptação ilegal de correspondência, por exemplo.

No sentido contrário, Ada Pellegrini (2000, p. 143) afirma que existe a "atipicidade constitucional", e que os preceitos constitucionais relevantes para o processo são garantias, interessam à ordem pública e à boa condução do processo, de forma que contrariar essas normas trará a ineficácia do ato processual, ou por nulidade absoluta, ou pela inexistência, pois a Constituição da República tem como inaceitável a prova alcançada por meios ilícitos. 
Também manifestando contra a admissibilidade, João Batista Lopes (2000, p. 209) alega que o sistema do país está demasiadamente vinculado ao fundamento constitucional da prova ilícita, e que sempre que as provas violarem direitos fundamentais previstos constitucionalmente não poderão ser admitidas como meio de prova.

E, por fim, há a teoria da proporcionalidade (NERY JR., 1997), que propõe um intermediário entre extremos, sendo diversas vezes adotada em casos de direito de família, tendo em vista que é uma forma de solucionar conflitos e, de acordo com Rizzato Nunes (2002, p. 34), o caso concreto irá apontar qual o caminho a ser trilhado para que o intérprete coloque em relevo esse ou aquele princípio. Dessa forma, o magistrado equilibra diferentes valores constitucionais, protegendo o bem jurídico mais relevante no caso em específico.

Estas correntes demonstram que a utilização de provas adquiridas de forma ilícita deverá ser averiguada caso a caso pelo julgador para que determine se deverá ser considerada ou não, já que esta não é uma matéria consolidada em nossa jurisprudência ou doutrina.

A título de exemplo, há um caso em que um dos cônjuges realizou a gravação não consentida de uma conversa de telefone em que ficava comprovado que o outro cônjuge deliberadamente fraudava o patrimônio comum. Na decisão, foram considerados diversos fatores, como a violação da intimidade, a ponderação do direito à prova, e principalmente, se a prova em questão foi fundamental para a descoberta da verdade. Vejamos:

AÇÃO PAULIANA. GRAVAÇÃO DE CONVERSA ENTRE MARIDO E MULHER. PEDIDO DE JUNTADA PELA ÚLTIMA. PROVA DE DEFRAUDAÇÃO DO PATRIMÔNIO COMUM. DECISÃO QUE CONSIDERAA PROVA COMO ILÍCITA. OFENSAAO DIREITO DA INTIMIDADE. DESCABIMENTO. APLICAÇÃO DO PRINCÍPIO DA PROPORCIONALIDADE. PONDERAÇÃO DO DIREITO À PROVA. LIMITAÇÃO QUE CEDE À PROVA RELEVANTE. INTERESSES DA BUSCA DA VERDADE E DA SEGURANÇA JURÍDICA QUE SACRIFICAM, NO CASO CONCRETO, A TUTELA DA INTIMIDADE. RESTRIÇÃO CONSTITUCIONAL SUPERADA PELA ORIGINALIDADE DA PROVA PARA A DESCOBERTA DA VERDADE. ASSIM, É RAZOÁVEL A UTILIZAÇÃO DE GRAVAÇÃO DE CONVERSA ENTRE MARIDO E MULHER, MESMO QUE UM DOS INTERLOCUTORES DESCONHEÇA A IMPRESSÃO SÔNICA FEITA PELO OUTRO.

A preservação da garantia constitucional da privacidade, por não ser absoluta, não pode servir para cometimento de injustiça, nem obstáculo invencível que venha a favorecer quem violou o direito material que alicerça a pretensão contraposta, cabendo ao juiz dar valor ao conteúdo da prova, independente do meio com que foi obtida, ainda que com superação de certos direitos consignados na Lei Magna ou na legislação ordinária. No âmbito do Direito de Família a prova tem singularidades que impõem um tratamento específico diversamente dos outros campos jurídicos, e que decorrem da natureza da relação conjugal, onde as violações do dever são clandestinas, embaraçando a sua visibilidade e constatação. O direito à intimidade, como qualquer outro, não pode sobrepor-se de maneira absoluta a outros dignos da tutela judiciária, podendo submeter-se ao direito à prova, também constitucionalmente assegurado, aplicando-se o princípio da proporcionalidade, aqui se ponderando favoravelmente os interesses ligados à reta administração da justiça e sacrificandose a privacidade. O direito à prova é o direito da parte em utilizar todas as provas de que dispõe para demonstrar a veracidade dos fatos em que se funda a pretensão e que seria inútil se não se vinculasse ao direito de aquisição da prova, desde que admissíveis e relevantes. Assim, o objeto do direito à prova é o direito da parte à prova relevante, que cede aos direitos fundamentais, desde que ela não detenha outra forma de comprovação. Desta forma, prevalecem os interesses da verdade e da segurança jurídica, restando à coletividade assegurar-se contra a obtenção ilícita com o manejo da responsabilidade civil ou penal para o autor que malferiu a moral. É razoável a produção de prova oriunda de gravação de conversa entre marido e mulher, em que se utilizaram meios comuns, mesmo que um deles desconheça a existência da impressão sônica, uma vez que não há quebra da privacidade. Agravo provido, para autorizar a produção do clichê sônico. (Agravo de Instrumento $n^{\circ} 70005183561$ da $7^{a}$ CC do TJRS, Rel. Desemb. José Carlos Teixeira Giorgis, j. em 12.03.2003).

Este caso da interceptação telefônica ocorre rotineiramente e exemplifica de forma clara o aproveitamento de um cônjuge da coabitação para armazenar provas contra o parceiro, não tão somente 
pelo fim de prejudicá-lo, mas para conseguir provar algum fato que não seria possível sem uma eventual gravação clandestina.

No caso relatado, o julgador decidiu pela consideração da prova obtida ilicitamente por considerar que a restrição constitucional foi superada pela imprescindibilidade da prova para a descoberta da verdade, não havendo outras provas que poderiam elucidar a questão, tendo sido, portanto, necessária a gravação.

Nas situações supracitadas, o acesso da parte às provas seria por meio de utilização indevida de materiais coletados durante um relacionamento. Sendo assim, não deverá ser desconsiderado o fato de que um dos ex-cônjuges invadiu a esfera mais íntima do outro, em momento que partilhavam de confiança e boa fé, na intenção de utilizar contra ele este material.

Como explanado no decorrer deste artigo, os cônjuges usualmente mantêm uma relação de companheirismo e confiança e, embora partilhem de uma vida comum, mantêm diversos direitos, sendo primordial a proteção de sua privacidade e de sua intimidade. Partindo desse pressuposto, a invasão dessa esfera íntima por parte de outro cônjuge, aproveitando-se da sua condição de convivência para armazenar conteúdo, é grave.

No entanto, é imprescindível que seja realizada uma análise concreta dos fatos para determinar se a prova é ou não imprescindível para o descobrimento da verdade real dos fatos, e se, por meio de uma ponderação de princípios, a violação da intimidade é um gravame menor do que o dano que está sendo causado pela outra parte.

Pontes de Miranda (1983, p. 131) narrou, ao tratar do direito ao sigilo e resguardo da personalidade, que se tratam de direitos que cedem diante de outros mais importantes a serem protegidos, como casos de direito à vida, à integridade física, à verdade ou à honra.

Não é possível definir de maneira taxativa qual lesão de direitos é mais severa, principalmente em casos que envolvam patrimônio e verbas de caráter alimentar. Além do mais, em qualquer tipo de situação dentro do direito de família, é necessário um exame atencioso e extrema cautela na tomada de decisões.

Cabe trazer, por fim, a lição de María Josefa Méndez Costa (2006, p. 37), que ensina que a família é o primeiro e mais fundamental, o mais específico, mais real e concreto encontro humano do homem e, por isso, tudo nela é fundamental, pois é a base de toda a sociedade.

\section{Conclusão}

A intimidade e a vida privada não devem cessar com a contração do matrimônio. Os direitos da personalidade são inatos, de forma que não há uma interrupção dos mesmos no momento em que duas pessoas decidem se casar.

Por diversas vezes, um dos cônjuges pode preferir guardar peculiaridades e informações íntimas de maneira reservada, sem compartilhá-las. Não há ilícito nisso, a não ser que esconda questões que dizem respeito ao outro cônjuge, que possam afetá-lo, ou caso descumpra os deveres concebidos no momento do casamento.

Quando um dos cônjuges, em momento posterior ao casamento, vale-se de informações obtidas unicamente por meio da relação que compartilhava anteriormente com o outro cônjuge para utilizá-las em seu benefício, causando prejuízos a outra parte, deverá haver uma apreciação do caso concreto.

Por diversas vezes as informações são obtidas ilicitamente por meio de interceptação telefônica, invasão de aparelhos telefônicos, armazenamento de mensagens e documentos sem autorização. Em razão da eventual ilicitude dessas provas, deverá haver um exame a respeito da forma que foram obtidas e se elas serão juridicamente válidas, ponderando-se os princípios envolvidos com a finalidade de descoberta da verdade real, sopesando os demais interesses existentes em cada caso. 


\section{Referências}

AMARANTE, Aparecida I. Responsabilidade civil por dano à honra. 6. ed. Belo Horizonte: Del Rey, 2005.

ANTUNES VARELA, J. M. Direito da família. 3. ed. Lisboa: Livraria Petrony, 1993.

BELTRÃO, Silvio Romero. Direitos da personalidade. São Paulo: Atlas, 2005.

BRASIL. Tribunal de Justiça de Minas Gerais. $3^{a}$ Câmara. Apelação Cível $\mathbf{n}^{\circ}$ 62.318. Relator:

Desembargador Milton Fernandes. 22 mar. 1984. RT 590/212.

BRASIL. Tribunal de Justiça do Rio Grande do Sul. Agravo de Instrumento $n^{\circ} 70005183561$ da $7^{\text {a }}$ CC do TJRS, Relator: Desembargador José Carlos Teixeira Giorgis. 12 mar. 2003. Disponível em: <http:// www1.tjrs.jus.br/site_php/consulta/consulta_processo.php?nome_comarca=Tribunal+de+Justi\%E7a\&ver sao $=\&$ versao_fonetica $=1 \&$ tipo $=1 \& i d \_c o m a r c a=700 \&$ num_processo_mask $=70005183561 \&$ num_processo $=70005183561 \&$ codEmenta=606506 \&temlntTeor=true $>$. Acesso em: $21 \mathrm{dez} .2016$.

CAHALI, Yussef Said. Divórcio e separação. 6. ed. São Paulo: RT, 1991. t. 1.

CAMBI, Eduardo. A prova civil, admissibilidade e relevância. São Paulo: RT, 2006.

CAMPOS, Diogo Leite de. Lições de direito da família e das sucessões. Coimbra: Almedina, 1990.

COELHO, Francisco Pereira; OLIVEIRA, Guilherme de. Curso de direito de família. Coimbra: Coimbra Editora, 2008. v. 1.

COSTA, María Josefa Méndez. Los princípios jurídicos em las relaciones de família. Buenos Aires: Rubinzal-Culzoni, 2006.

COSTA JUNIOR, Paulo José da. O direito de estar só: tutela penal da intimidade. 4. ed. São Paulo: RT, 2007.

COSTA JUNIOR, Paulo José da. O direito de estar só: tutela penal da intimidade. São Paulo: RT, 1970.

DABIN, Jean. Le droit subjectif. Paris: Dalloz, 1952.

DE PLÁCIDO E SILVA. Vocabulário jurídico. 15. ed. Rio de Janeiro: Forense, 1999.

DIDIER JÚNIOR. Fredie. Comentários ao código civil brasileiro: do direito de família. Direito Patrimonial (Arts. 1.639 a 1.783). Rio de Janeiro: Forense, 2005. 15 v.

DINIZ, Maria Helena. Curso de direito civil: responsabilidade civil. 17. ed. São Paulo: Saraiva, 2003. v. 7.

FERNANDES, Milton. Proteção civil da intimidade. São Paulo: Saraiva, 1977.

FERREIRA FILHO, Manoel Gonçalves. Direitos humanos fundamentais. São Paulo: Saraiva, 1999.

GOMES, Orlando. Direito de Família. 4. ed. Rio de Janeiro: Forense, 1981.

GONÇALVES, Andrey Felipe Lacerda; BERTOTTI, Monique; MUNIZ, Veyzon Campos. O direito fundamental à privacidade e à intimidade no cenário brasileiro na perspectiva de um direito à proteção de dados pessoais. Revista de Direito Privado: RDPriv., São Paulo: RT, a. 14, v. 54, n. 4, p. 45-62, abr./ jun. 2013.

GRINOVER, Ada Pellegrini; FERNANDES, Antonio Scarance; GOMES FILHO, Antonio Magalhães. As nulidades no processo penal. 6. ed, São Paulo: Revista dos Tribunais, 2000.

LEITE, Eduardo de Oliveira. Direito civil aplicado. São Paulo: Revista dos Tribunais, 2015. 5 v.

LÔBO, Paulo. Direito Civil: famílias. São Paulo: Saraiva, 2010.

LOPES, João Batista. A prova no direito processual civil. 2. ed. São Paulo: RT, 2002.

MARTINS-COSTA, Judith; BRANCO, Gerson Luiz Carlos. Diretrizes teóricas do novo código civil brasileiro. São Paulo: Saraiva, 2002. 
MORAES, Walter. Direito à própria imagem (I). Revista dos Tribunais, São Paulo: Revista dos Tribunais, ano 61, v. 443, p. 1089-1117, set. 1972a.

MORAES, Walter. Direito à própria imagem (II). Revista dos Tribunais, São Paulo: Revista dos Tribunais, ano 61, v. 444, p. 1119-1145, out. 1972b.

MOTTA, Carlos Dias. Direito matrimonial e seus princípios jurídicos. São Paulo: RT, 2007.

NERY JR., Nelson. Proibição da prova ilícita. 4. ed. São Paulo: Saraiva, 1997.

NERSON, Roger. Jurisprudence française en matière de droit civil. Revue Trimestrielle de Droit Civil, Paris, ano 69, n.1, p. 360-376, avr.-juin. 1970.

NUCCI, Guilherme de Souza. Código penal comentado. 5. ed. São Paulo: Revista dos Tribunais, 2005.

NUNES, Rizzato. O princípio constitucional da dignidade da pessoa humana, doutrina e jurisprudência. São Paulo: Saraiva, 2002.

PEDROSO, Fernando de Almeida. Prova penal. Rio de Janeiro: AIDE, 1994.

PEDROSO, Fernando de Almeida. Processo penal. O direito de defesa: Repercussão, amplitude e limites. Rio de Janeiro: Forense, 1986.

PEREIRA, Lafayette Rodrigues. Direitos de família. Brasília: Senado Federal, 2004.

PINHEIRO, Jorge Alberto Caras Altas Duarte. 0 núcleo intangível da comunhão conjugal: os deveres conjugais sexuais. Coimbra: Almedina, 2004.

PONTES DE MIRANDA, F. C. Sistema de ciência positiva de direito. Campinas: Bookseller, 2000. t. 4. PONTES DE MIRANDA, F. C. Tratado de Direito Privado. Rio de Janeiro: Borsoi, 1971. v. 7. t. II.

PONTES DE MIRANDA, F. C. Tratado de Direito Privado. São Paulo: RT, 1983, v.7, p.131.

RODRIGUES, Silvio. Direito Civil. 24. ed. São Paulo: Saraiva, 1994. v. 1.

SAMPAIO, José Adércio Leite. Direito à intimidade e à vida privada: uma visão jurídica da sexualidade, da família, da comunicação e informações pessoais, da vida e da morte. Belo Horizonte: Del Rey, 1998.

SANTOS, Antonio Jeová. Dano moral da internet. São Paulo: Método, 2001.

SCHLÜTER, Wilfried. Código civil alemão: direito de família. Porto Alegre: Sergio Antonio Fabris Editor, 2002.

SOUSA, Lourival de Jesus Serejo. As provas ilícitas e as questões de Direito de Família. Revista Brasileira de Direito de Família, Porto Alegre, v. 2, p. 10, jul./ago./set. 1999.

SZANIAWSKI, Elimar. Direitos de personalidade e sua tutela. 2. ed. rev. atual. e ampl. São Paulo: Revista dos Tribunais, 2005.

Recebido em: 12/06/2017

Aprovado em: 06/10/2017 